\title{
SURFACE CRYSTALLIZATION OF AQUEOUS SALT SOLUTION UNDER OVERHEATING AND OVERCOOLING
}

\author{
Vladimir Nakoryakov ${ }^{1}$, Sergei Misyura ${ }^{1, *}$ and Vladimir Morozov ${ }^{1}$ \\ ${ }^{1}$ Institute of Thermophysics of SBRA, Novosibirsk, Russia
}

\begin{abstract}
The investigation of the surface crystallization with low negative and high positive temperatures were carried in the paper. Crystallization curves for distillate $\left(T_{\mathrm{s} 0}=-9^{\circ} \mathrm{C}\right)$ and different mass salt concentrations $\mathrm{NaCl}\left(T_{\mathrm{s} 0}=80^{\circ} \mathrm{C}\right)$ were obtained. Experimental data indicate that the crystallization centers influence each other and the number of centers does not change with time. The maximum speeds for the crystallization front reached $0.3-0.5 \mathrm{~m} / \mathrm{s}$. There are a significant anisotropy and a curvature of crystallization front. The surface kinetics should be considered to clarify the rate of freezing and melting of ice in modeling global warming.
\end{abstract}

\section{Introduction}

Typically, crystallization models examine large volumes, the independence of crystalline centers, three-dimensional crystallization and often do not take into account the surface phenomena in the description of global warming. A kind of kinetic curves depend on the dimensionality of the growth centers of the new phase [1]. A deviation from equilibrium depends on heat transfer and the high supercooling $[2,3]$. Another important challenge is the crystallization of salt solutions at a high salt concentration in adsorption heat pumps and in apparatus for chemical technologies. Absorbers and desorbers operate with solutions having high salt concentration. There is a risk of local areas formation of partial surface crystallization during transient modes of pumps. The behavior of solutions and mixtures studied in [4-7]. Crisis phenomena at phase transitions are considered in [8]. Combustion of fuel in a gas-droplet mixture is considered in [9]. Thermal measurement technique discussed in [10].

\section{Experimental data}

The investigation of the surface crystallization with low negative and high positive temperatures were carried in the paper. The heating and the cooling rate was $1{ }^{\circ} \mathrm{C} / \mathrm{min}$. External pressure was $1 \mathrm{~atm}$. Ambient temperature was $20^{\circ} \mathrm{C}$. The whole setup was in a closed housing with a relative humidity less than $10 \%$. The diameter of the working

*Corresponding author: misura@itp.nsc.ru 
cylinder with the solution was $15 \mathrm{~mm}$, material was brass. The temperature of the liquid surface was measured by a high-speed thermal imager. The error of the surface temperature was within $1{ }^{\circ} \mathrm{C}$. fig. 1 shows photographs of the thermal image for surface crystallization front. Red corresponds to $0{ }^{\circ} \mathrm{C}$.

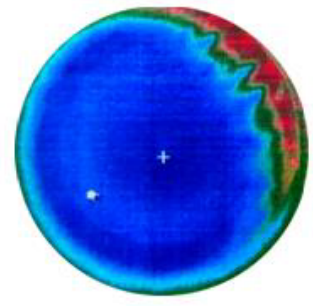

$\mathbf{t}=\mathbf{0 . 0 5} \mathrm{s}$

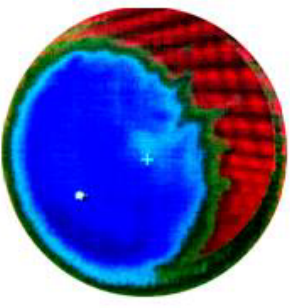

$\mathbf{t}=\mathbf{0 . 1 s}$

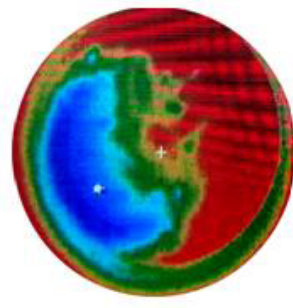

$\mathrm{t}=\mathbf{0 . 2 \mathrm { s }}$

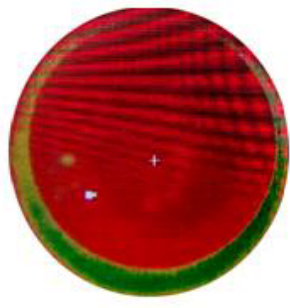

$\mathrm{t}=\mathbf{0 . 3 \mathrm { s }}$

Fig. 1. Thermal pictures of the surface crystallization of distillate $\left(T_{\mathrm{s} 0}=-9^{\circ} \mathrm{C}\right)$.

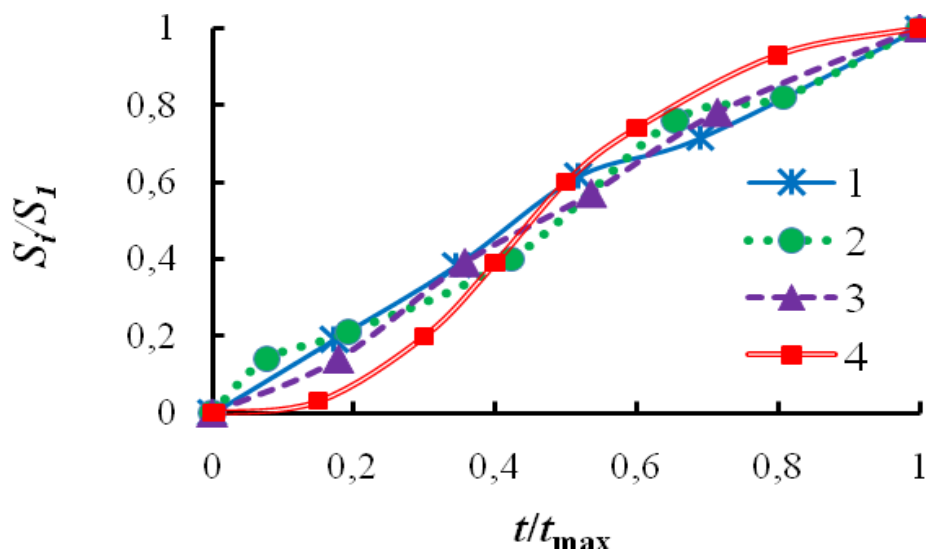

Fig. 2. Crystallization kinetics for the mass concentration of the salt solution $\mathrm{NaCl}$ : 1 - distillate, 2 $C_{0}=0.1 \%, 3-C_{0}=1 \%\left(T_{\mathrm{s}}=(263-264) \mathrm{K}\right), 4-C_{0}=26 \%\left(T_{\mathrm{s}}=353 \mathrm{~K}\right)$.

Fig. 2 shows crystallization curves for different mass salt concentrations $\mathrm{NaCl}$. The growth rate of the curves (1-3) is quasi-linear and curve 4 corresponds to curve 1, 2 (fig. 3 ). It is obvious that the growth rate of the crystal film thickness decreases with increasing time. Then the experimental curve for the dimensionless volume $V_{\mathrm{i}} / V_{0}=f(t)$ will have the form 4 in fig. 3 . The character of the crystallization curve for independent crystals centers depends on the dimensionality and has the general form $V_{\mathrm{i}} / V_{0}=1-\exp \left(-k w c^{\mathrm{nl}} t^{\mathrm{n} 2}\right)$, where $k$ is the coefficient, $w$ is the speed of the new centers emergence, $c$ is the crystal growth velocity, the coefficients $n$ depend on the type of crystallization (dimensionality). Curve 1, 2, 3 correspond to crystal growth for three-dimensional, two-dimensional and onedimensional growth, curve 4 for the two-dimensional growth when $w=0$. Experimental data (Curve 4) indicate that the crystallization centers influence each other and the number of centers does not change with time $(w=0)$. The maximum speeds for the crystallization front reached $0.3-0.5 \mathrm{~m} / \mathrm{s}$. 


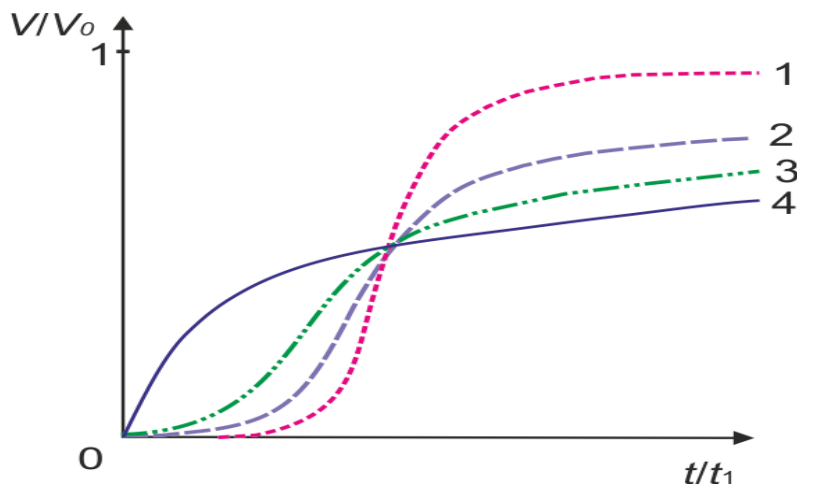

Fig. 3. Kinetic curves of crystallization.

\section{Conclusion}

The high rate of surface crystallization was observed at high overheating and high supercooling. At the same time there are a significant anisotropy and a curvature of crystallization front. The surface kinetics should be considered to clarify the rate of freezing and melting of ice.

\section{Acknowledgments}

This work was supported by the Russian Foundation for Basic Research, project No. 16-0800488 .

\section{References}

1. N.N. Sirota, Crystallization and phase transitions (Publisher BSSR, Minsk, 1962)

2. A.A. Chernov, J. Engineering Thermophys. 18, 238 (2009)

3. A.A. Chernov, A.A. Pil'nik, JETP Letters 102, 526 (8) (2015)

4. D. Feoktistov, E. Orlova, A. Islamova, EPJ Web Conf. 110, 01018 (2016)

5. S.Ya. Misyura, Int. J. Therm. Sci. 92, 34 (2015)

6. S.Y. Misyura, Exp. Thermal Fluid Sci. 75, 43 (2016)

7. A.N. Pavlenko, V.E. Zhukov, N.I. Pecherkin, O.A. Volodin, A.S. Surtaev, X. Li, X. Gao, L. Zhang, H. Sui, H. Li H, J. Engineering Thermophys. 24, 210 (2015)

8. S.Y. Misyura, Exp. Thermal Fluid Sci. 70, 389 (2016)

9. S.Y. Misyura, Energy 103, 430 (2016)

10. S.L. Elistratov, E.Yu. Slesareva, EPJ Web Conf. 82, 01060 (2015) 